\title{
Research on the Tourism Image Strategy of Small Towns Based on CI Theory
}

\author{
Pingqing Zhang \\ Yantai Nanshan University \\ Longkou, Shandong, China 265713
}

\author{
Yang Wang \\ Yantai Nanshan University \\ Longkou, Shandong, China 265713
}

\begin{abstract}
In the material space where we live, villages, market towns and towns are several levels and stages that human settlements develop from low level to high level. Towns are symbols of high civilization in the process of social development of human being, and represent the level of civilization that human conquer nature and remake nature and furthest meet the needs of human. The development and research on the construction of towns are comparatively mature and perfect and have filled in every field. For the construction of relatively scattered small towns with small scale, weak economic basis and no high level of civilization, the research of all kinds of disciplines is relatively weak. The construction of small towns is a systems engineering with wide covering range and strong policy consideration. It has vital practical significance to ensure the construction and sound development of tourism image of small towns, promote the construction of socialism new countryside and implement rural modernization in our country through deeply researching scientific theories and methods of its planning and construction such as relevant policy, constructing mode and operation law, and using CI theory to solve problems existed in the construction and planning process of small towns
\end{abstract}

Keywords-construction of small towns; tourism image strateg; CI theory

\section{INTRODUCTION}

In face of the same pattern of tourism image construction of small towns in our country, the tendency towards no differentiation and the current situation that tourism construction in small towns develops blindly, systematic and scientific design theory and methods are more needed to reorganize the integrated environment of small towns, shape distinctive, unique and modern tourism image of small towns, establish positive, healthy and upward cultural construction concept of towns at macro level, use behavioral expression of mesoscopic principal part and micro recognition system of visual landscape in towns to make small towns become the pillar and new force of national economy to maintain environmental ecological balance and sustainable development.

\section{DEVELOPMENT HISTORY OF SMALL TOWNS}

The urbanization under the promotion of development of small towns is the outstanding manifestation of China's modernization process after the reform and opening up. In September 1983, Mr. Fei Xiaotong put forward the proposition of "small town, big problem", which cause attention and research of small towns in our country. Since the 1980s, under the guideline of "unified planning, rational distribution, adjusting measures to local conditions, distinguishing features, protection of cultivated land, optimization of environment, comprehensive development and matched construction", the functional quality and environmental quality of small town construction in our country have got considerable improvement and the theory and methods of small town planning have got step-by-step improvement and development.

On June 13, 2000, the Central Committee of CPC and the State Council point out in Several Opinions on Promoting Healthy Development of Small Town: "Developing small towns is the inevitable course to realize rural modernization in our country." "At present, the time and condition to quicken the urbanization have matured. It should be the task of rural reform at present and for a relatively long period to seize the opportunity and guide the healthy development of small towns at the right moment." The Ministry of Construction and local governments have successively formulated some laws and regulations, and technical specifications. By the end of 2009, the overall planning of towns compiled and accumulated in our country has reached 39,555 , which cover $85.91 \%$ of the total number of towns; 15,480 construction planning of adjustment and improvement of organic towns has been accumulatively compiled, which cover $89.29 \%$ of the total number of organic towns. There are 7,550 pilot projects for construction of organic towns in our country. It plays a certain role in guiding the healthy development of small towns, greatly promotes the construction and development of small towns.

\section{CuRRent Situation AND CRisis OF DEVElopment OF SMALL TOWNS}

The development experience of towns in various countries in the world shows that industrialization and urbanization are development processes that influence and promote each other. For China, under the circumstances of intervallic development patterns and urban-rural gap and income level, the structure of urban and rural segregation and "city-countryside dualization" is formed. When the urban and rural development completes the change of industrial structure, the changes of employment structure, space structure and survival mode are unfinished. Since the reform 
and opening up in 1979, small towns have got rapid recovery and development. For small towns in 1980s, the number increases; the scale is enlarged; social functions tend to reach perfection; its emissive power, attraction and comprehensive service ability towards the surrounding community improve significantly. In the aspect of macro layout, some areas form a reasonable system of small towns. Some star towns stand out and open a new road for the development of small towns. However, most of the existing small towns in China are spontaneously formed in history. Even though it has natural fitness, at the same time, there are certain blindness and imbalance. Besides, the construction of small towns lacks scientific planning and management. So a series of problems appear. For example, the number of small towns is large; the scale is small; the development level of most small towns is low; the function is not perfect enough; the distribution of small towns in many areas are imbalance and the structure is unreasonable, etc. In addition, insufficient fund, critical shortage of talents, land wastage, environment pollution, unreasonable system and imperfect management all seriously obstruct the healthy development of small towns. Under this state of development, it is necessary and the responsibility of us to rethink and understand the theory and practice of "the construction of small towns"

\section{CI STRATEGY OF THE CONSTRUCTION OF SMALL TOWNS}

As a kind of systematic idea and theory, after more than half a century of development, CI strategy has become a "soft science" that integrates knowledge of many subjects and has strong practicality. It is also an advanced culture that has influence on various countries in the world and will show vitality even more. In theoretical exploration of the construction of small towns in China, it is a powerful means to reshape the tourism image of small towns by guiding CI strategy into the construction of towns and establishing CIS system of small towns.

The tourism image system of towns (CIS of towns for short) refers to the systems engineering that under the guidance of planning and design, shape the image of all aspects of towns and spread it with the help of media or other channels, in order to make the public form unified value that is rich in individual features toward towns. The town is a large system. CIS of towns is a kind of cultural manifestation in this system, which predestinate that CIS of towns is a complicated social system.

The establishment of CIS of towns involves political, economic, cultural and many other fields, which is a huge system. System is an entirety that all elements connect organically. The tourism image systems of towns include three subsystems: management idea system of towns (MIS), subject behavior system of towns (BIS), and visual landscape system of towns (VIS). When constructing the tourism image of towns, it is necessary to start from three aspects of macro management concept planning, code of conduct of mesoscopic principal part and micro visual landscape design and then plan and design systematically.

\section{A. Macro Planning of Operation Principle}

In order to speed up the pace of tourism image construction of small towns, it is necessary for us to establish the concept of "town management", take towns as stateowned property to manage, use the means of market economy to regroup and operate natural capital, man-power capital and correlative outstretched capital that form the space and function carrier of small towns, furthest vitalize the stock and attract the incremental to take a road to marketization of construction of towns that build and prosper towns based on towns.

Who are we? How should we do and for whom? How to do and show things that we want to? These three questions cannot be completely the same in any town, but these three parts commonly form the ideality of small towns and we can construct new images inside and outside towns based on them. It is the most critical part to successfully introduce CI and establish operation principle of small towns. The purpose is to make small towns truly see themselves clearly. It is essential to make the comprehension and cognition of all the citizens reach an agreement and then use images to express the spirit of small towns and use service to reflect this spirit. Therefore, the beginning of CI planning is to build and establish the macro new concept of small towns operation, not to immediately start on the micro visual landscape design.

When plan and design MIS of small towns, we should crystallize it into basic elements of operation principle and relevant application element. Basic elements of operation principle include four items: construction mission of small towns, management philosophy, strategic objective and level of behavior. Application elements of mind identity include spirit of small towns, value of small towns, management policy and management style of small towns, slogans of tourism image of small towns, etc. In order to establish the identification of small towns, we must definitely construct the above concepts and there are possibilities to rebuild after a certain period of time.

\section{B. Code of Conduct of Mesoscopic Principal Part}

For the lead-in of CI, if we cannot unify the understanding and reach an agreement within people in small towns and if there are no supports and joint efforts of all the people and enterprise and public institutions to form a warm and fervent atmosphere, it is impossible to effectively promote CI and give play to the influence of CI only by relying on the efforts of government leaders. Tourism image of small towns is the integration of images of all the elements in small towns. The power of tourism image shaping of small towns comes from the join forces of all the people in towns. The lead-in and implementation process of $\mathrm{CI}$ is the process of common participation and input of all the people in essence, and it is a series of permanent behaviors that have no end. The operational level of tourism image of small towns covers a wide range, and the management control subjects are distributed. In the process of operation, it can fully reflect the structural meaning of systems engineering, for example, who is the subject of tourism image construction of towns? The government must step in; 
enterprises must participate in; citizens must involve in and market-oriented relations must form, etc.

BIS of small towns include three aspects of content: government behavior, enterprise behavior and behaviors of citizens.

Governmental behavior. Government is the administrator of towns. The quality of government image directly influence the quality of tourism image of towns, so an honest, efficient, democratic and open group image of government cadres must be built. The group image of cadres is an important part of tourism image of towns. Especially the image of leading cadres must achieve the goal that care about common people, be honest in performing their official duties, make scientific decisions and be democratic and fair. Only good government image can open the new situation of tourism image construction of small towns and boost the comprehensive development of towns;

Enterprise behavior. Speed up the development of township enterprises and reconstruct the image of township enterprises and goods image. The image of township enterprises and goods image are important parts of tourism image construction of towns. When shaping tourism images of small towns, we must pay attention to the shaping of image of township enterprises, strengthen the publicity of township enterprises, actively expand the scope of investment promotion and capital introduction, and set up the effect of famous-brand products. Besides, we should use the image of township enterprises to boost the construction and development of tourism image of towns.

Behaviors of citizens. Improve the comprehensive quality of citizens, form a diligent, enthusiastic, civilized and open citizen group that has relatively strong cultural, ethical and legal awareness, reflect the true, the good and the beautiful of the inner pursuit of citizens on concrete tourism image construction of small towns. Attach importance to traditional custom and national features of small towns under the background of national cultures. People's actions and activities should keep the succession and inheritance of cultural tradition, deeply excavate cultural and artistic activities that have traditional features, and enlarge their domestic and international influences.

\section{Micro Visual Landscape Design}

VIS, the visual landscape system of towns, is to integrate the requirements of the conception of MIS and need of BIS, use distinct visual image to transmit ideas of small towns and value information existing in the society. Small towns should unify the performance of visual identity, and make it have good recognition function. From this point of view, so far many towns have lacked adequate awareness. It exactly has more important significance on small towns in our country that are at the present stage.

Small towns make the best of elements such as their natural conditions, historical relics and cultural tradition to create the overall appearance of towns. On the basis of general planning of towns, they proceed with the design of towns and visual environment landscape. The landscape design factors of small towns usually include identification of towns, spatial arrangement of towns, town square, and environment of living area and infrastructure construction of towns. Through elaborate organization and layout of landscape elements of towns, use various techniques of environmental art design to form landscape array that shows town identity; use smooth and ease town space layout, elegant and graceful cultural places that have emotional appeal, fresh and bright, natural and interesting greening system to form attractive and good visual landscape system of towns.

\section{CONCLUSION}

The lead-in and implementation of CI strategy in small towns must take local characters and economic base of small towns as premises, proceed from reality in all work, make wide and deep research and analysis on historical development, cultural style and features, tourism resources and existing images and environment of small towns, and provide full and accurate materials for the form of planning and design and the location of tourism image of small towns. Thus the shaping of tourism image of small towns can stand higher. Otherwise, the imagined design of images that are entirely groundless can only be an empty hole invites the wind, causes that the image breaks away from the reality and actual history and becomes false and exist in namely to have bad influence on the environment.

\section{REFERENCES}

[1] Qiu Baoxing. Reconstruction of Microcirculation of Towns-A Big Trend Is about to Happen [J], Research on Town Development, 2011(5)

[2] Wu Yizhou, Wang Lin. Space Performance of Urbanization in Our Country: Analytical Framework, Realistic Difficulties and Optimized Path [J], Planners, 2012(9)

[3] Cheng Liantao. Research on Six Major Problems in the Construction of Tourism Image of Small Towns in Guizhou [J], Construction of Small Towns, 2012(8)

[4] Kuang Qifang. Thinking on Improvement and Optimization of Development Control Planning System of Small Towns [J], Chinese and Overseas Architecture, 2010(8)

[5] Kuai Yanli, Liu Haiyan. Discussion on the Current Situation, Existing Problems and Perfection of Measures of Planning Formulation of Towns in Our Country [J], Planners, 2010(6) 